\title{
PODER DE COMPRA DEL ESTADO \\ CAPITALISTA Y FINANCIACIÓN \\ COMPETITIVA DE LA I+D. UN ANÁLISIS \\ MARXIANO DE LA TRANSFORMACIÓN \\ DE LA ESTRUCTURA ECONÓMICA DE LA \\ PRODUCCIÓN CIENTIIFICA
}

\section{CAPITALIST STATE'S PURCHASING POWER AND REYD COMPETITIVE FUNDING. A MARXIAN ANALYSIS ON THE TRANSFORMATION OF THE ECONOMIC STRUCTURE OF THE SCIENTIFIC PRODUCTION}

Luis Arboledas-Lérida

Universidad de Sevilla

luis.arbooledas@gmail.com

https://orcid.org/0000-0003-2392-5885

Recibido: noviembre de 2019

Aceptado: diciembre de 2019

Palabras clave: Financiación de la ciencia; acumulación capitalista; poder de compra del Estado; Rosa Luxemburgo.

Keywords: Science funding; capitalist accumulation; State's purchasing power; Rosa Luxembourg.

Resumen: el presente artículo aborda la transformación de la estructura económica de la ciencia que viene acaeciendo desde los años '80 del siglo pasado, a partir de los postulados desarrollados por Rosa Luxemburgo respecto del contradictorio movimiento expansivo de la relación social capitalista (acumulación del capital) y el papel desempeñado en el mismo por la demanda estatal. En concreto, se pretende demostrar que los cambios ocurridos en los últimos tiempos en materia de financiación de la denominada "ciencia pública» responden a la progresiva subsunción de esta esfera de la producción social a la lógica del valor; y que la demanda estatal, como momento particular de la acción del Estado capitalista, media necesariamente este despliegue de la forma capitalistas de producción al interior del ámbito de la academia.

Abstract: this article analyses the transformation undergone by the economic structure of the scientific production from the '80s onwards, taking as a point of departure those postulates fleshed out by Rosa Luxembourg with respect to the contradictory expansive movement of the capitalist social relationship (capital accumulation) and the role played by the state's purchasing power on such. More 
precisely, we aim at demonstrating that changes happening on science funding policies over the last decades are grounded on the progressive subsumption of the "public science» to the logic of value; and, furthermore, that the demand from the capitalist State, as a particular moment of the latter's action, necessarily mediates the unfolding of capitalist form of production within the academic sphere.

\section{Introducción}

Decía Marx (2000) que la mercancía era un "jeroglífico social" que la Economía Política no había sido capaz de descifrar. Algo semejante ocurre con la transformación de la estructura económica de la investigación científica y las leyes que lo rigen. Pese a los intentos de ofrecer una explicación hechos desde las más diversas corrientes del pensamiento, el enigma continúa irresoluto. Por más vueltas que le dé, lo ponga de un lado o del otro, del derecho o del revés, la ciencia social sigue sin comprender el por qué de los cambios en el modelo de financiación de la ciencia.

Véase, a este respecto, la lectura que se hace de tal fenómeno en tanto que «mercantilización del conocimiento» 0 «mercantilización de la ciencia». Hans Radder (2010), por ejemplo, considera que son dos las acepciones que este concepto puede tener. Una primera definición, más estrecha, se atiene al fenómeno mismo de la compraventa del conocimiento científico. Con ésta no alcanza sino a registrar lo que es evidente de por sí, así carece de toda capacidad exegética. La segunda acepción que propone Radder es, a su propio juicio, más amplia, ya que abarca todo el espectro de fenómenos de la actividad académica contemporánea en los que prevalece la racionalidad económica frente al resto de valores epistémicos y extraepistémicos de la ciencia (conforme a la definición de Echevarría, 2002). Así, los libros de contabilidad de laboratorios o universidades serían para este autor prueba perentoria y suficiente de que la ciencia está mercantilizada. Esta segunda acepción se connota por sí misma, no hace falta añadir más.

Pero hay ideas aún más descabelladas. Otro académico famoso por su actitud crítica con las actuales transformaciones en el campo de la producción científica, Daniel Kleinman, considera que es la «cultura del emprendimiento» que recorre de arriba abajo la academia estadounidense - cuyos orígenes él cree poder rastrear hasta los mismos albores de las instituciones superiores de docencia y cienciaes la causa última de los cambios en su estructura económica (Kleinman, 2010). Ahora bien, ¿qué es lo que determina esta «cultura del emprendimiento»? El silencio es toda la respuesta que Kleinman está en condiciones de ofrecer.

Mejor suerte no correo el jeroglífico social de la transformación económica de la actividad académica en manos de economistas o teóricos de la Economía Crítica; incluso entre sus corrientes críticas. El "realismo crítico" de David Tyfield (2012) le lleva a negar de plano la posibilidad de la mercantilización de la ciencia, en tanto que la valorización del saber es fragmentaria, altamente inestable y depende en grado sumo, según consigna el autor, de "modalidades de producción extracapitalistas". También los académicos de raigambre postoperaísta trabajando en la materia, como Yann Moulier-Boutang 
o Enzo Rulliani, son de este mismo parecer. Aquí, la cuestión gira en torno a la ontología material de las mercancías cognitivas y la posibilidad o imposibilidad de su subsunción a la lógica del valor (para una crítica mordaz y fecunda desde posiciones marxianas a este respecto, véase Starosta y Caligaris, 2017, cap. 9). El presupuesto del análisis es que las mercancías cognitivas desbordan en virtud de su propia naturaleza los límites de la producción capitalista; cualquier intento de mercantilizar el trabajo de universidades y centros de investigación está llamado al fracaso. Se aplicarán "cercamientos» (Moulier-Boutang, 2004), claro, pero la tendencia inmanente es la de superar las formas enajenadas de la producción social en el capital, también en lo referente a la actividad académica.

Ante las deficiencias de todos los planteamientos previos, este artículo se propone un camino alternativo para aprehender las leyes que rigen la transformación de las formas sociales de organización del trabajo científico. Mediante la reproducción del concreto que a esta investigación ocupa mediante el método dialéctico, es decir, la reproducción ideal de lo concreto mediante el pensamiento (Marx, 2005; Íñigo Carrera, 1992; 2007), procuraremos determinar cuáles son las potencias realizadas en los recientes cambios de la estructura económica de la producción científica; para, de tal modo, organizar y regular nuestra propia acción social respecto de aquellas.

Si el capital es la potencia social que lo domina todo, como afirmase Marx (2000), ni qué decir tiene que los cambios en la estructura de financiación de la ciencia no pueden explicarse por fuera del movimiento contradictorio del capital mismo, es decir, del propio despliegue de la valo- rización del valor, de la acumulación del capital. Éste debe ser, por consiguiente, el punto de partida de la investigación. Pero, para arribar hasta aquí, habrá que explicar primero la acumulación del capital misma. Esto hace del proceso de conocimiento dialéctico un "proceso de reconocimiento" (Íñigo Carrera, 1992), en tanto que habremos de avanzar por sobre las formas generales de la acumulación del capital que Rosa Luxemburgo desvelara y condensara en La acumulación del capital (Luxemburgo, 1975). El retorno sintético hacia las manifestaciones exteriores del despliegue de la relación social capitalista en la esfera científica del trabajo social nos permitirá situar a estas en su determinación correspondiente. En otros términos: es a partir del análisis hecho por la revolucionaria polaca respecto del curso histórico de la acumulación del capital y su expansión a través del «medioambiente precapitalista», que se pretende aprehender el contenido real de la transformación de la estructura económica de la actividad científica.

Conforme a tal propósito, el artículo se estructura como sigue: el primer epígrafe consigna brevemente aquellos cambios más relevantes en el modelo de financiación de la ciencia contemporánea; en el segundo, se comentan y desarrollan las principales conclusiones alcanzadas por Rosa Luxemburgo a colación de la acumulación del capital, haciendo especial hincapié en el papel desempeñado por la acción estatal en su unidad material constitutiva, de un lado, y en el proceso de conquista, dominación y disolución de las formas sociales del trabajo que predominan en el «medioambiente precapitalista» a través del cual la relación social capitalista se expande, por el otro. El tercer epígrafe se consagra a hacer trasla- 
ción de las conclusiones alcanzadas en el análisis de las formas generales de la acumulación del capital al concreto que a esta investigación ocupa, es decir, la transformación de las formas sociales de la producción científica. Ello pondrá en relieve que el contenido real de este proceso, la necesidad que realiza, es el despliegue de la relación social capitalista al interior de la esfera científica. El trabajo se cierra recapitulando sobre los hallazgos hechos y aportando una lectura política de los mismos. En este apartado cristaliza la necesidad que mueve y recorre toda la investigación, que no es otra que la de organizar de forma plenamente consciente nuestra acción respecto de las potencias del objeto de nuestro análisis enfrenta y nuestro pensamiento reproduce, valiéndose del método dialéctico.

\section{La transformación económica de la ciencia}

La realidad económica de la actividad investigadora ha sido subvertida por completo en el curso de las últimas décadas, al punto de que puede hablarse de una «revolución praxiológica» (Echevarría, 2003) en la ciencia que comenzó a fraguarse en los años '80 del siglo pasado. Pero tal revolución no atañe en exclusiva, ni siquiera principalmente, al contenido de la investigación, sino a la forma social en que el conocimiento es producido.

Son dos los momentos particulares a destacar de este proceso histórico. De un lado, encontramos el avance de la inversión privada en Investigación y DesarroIlo (I+D) en el conjunto de los Sistemas Nacionales de Ciencia y Tecnología (SNCyT, en lo sucesivo), particularmente, en los países capitalistas más avanzados. El peso relativo del gasto privado respecto del público no ha dejado de crecer en el último medio siglo. A día de hoy, la distribución promedio para el conjunto de los países de la OCDE se sitúa en un 60 - 40 (OCDE, 2019), con casos extremos como los de Corea del Sur o Japón, donde las distancias se agudizan. No hay duda de que ésta es una tendencia general de la actividad científica global; y que son los países más avanzados en términos científicos y tecnológicos los que marcan el paso a seguir por el resto. La Tabla 1 recoge datos de esta distribución relativa del gasto interno en $1+D$ de algunas de las naciones más potentes en materia de ciencia y tecnología para el año 2016, último del que se dispone de registros completos para la mayoría de ellas.

El predominio inapelable del gasto empresarial que las estadísticas constatan, no ha sido una constante desde los orígenes de los SNCyT. Hasta finales de la década del '70, el Estado era el organismo financiador y ejecutor de la ciencia por excelencia, sufragando masivamente el trabajo científico que tenía su locus en universidades y Organismos Públicos de Investigación. Por supuesto, esto no exime de que hubiese importante inversión privada en I+D, pero uno y otro sector procuraban mantener la más estricta separación, tal y como prescribiesen los más importantes responsables de la política científica de la época (véase, por ejemplo, Bush, 1945).

Como segundo momento particular de la transformación de la forma social de la producción científico, aparece el cambio de orientación en las políticas de asignación y emplazamiento de recursos para investigación por parte del Estado y sus agencias científicas. Las renovadas directrices del modelo de financiación de la denominada «ciencia pública» se con- 
Tabla l. Distribución del gasto total en I+D entre los sectores público y privado en diferentes países de la OCDE

\begin{tabular}{|lcc|}
\hline PAIS & $\begin{array}{c}\text { PORCENTAJE DE } \\
\text { INVERSIÓN PRIVADA }\end{array}$ & $\begin{array}{c}\text { PORCENTAJE DE } \\
\text { INVERSIÓN PÚBLICA }\end{array}$ \\
\hline Estados Unidos & $63,2 \%$ & $23,56 \%$ \\
\hline Gran Bretaña & $51,77 \%$ & $26,26 \%$ \\
\hline Corea del Sur & $75,42 \%$ & $22,68 \%$ \\
\hline Japón & $78,09 \%$ & $15,02 \%$ \\
\hline China* & $76,48 \%$ & $20,03 \%$ \\
\hline Unión Europea -28 & $54,64 \%$ & $31,7 \%$ \\
\hline Alemania & $65,22 \%$ & $28,52 \%$ \\
\hline Francia & $54,04 \%$ & $34,81 \%$ \\
\hline España & $46,7 \%$ & $39,55 \%$ \\
\hline Suecia & $57,26 \%$ & $N / D$ \\
\hline Dinamarca & $58,31 \%$ & $28,56 \%$ \\
\hline Finlandia & $56,99 \%$ & $28,87 \%$ \\
\hline Total OCDE & $62,08 \%$ & $25,81 \%$ \\
\hline
\end{tabular}

Fuente: elaboración propia a partir de OCDE (2019): Main Science and Technology Indicators.

* Nota: China no forma parte de la OCDE, aunque los datos de su inversión en I+D sí están disponibles en la base de datos del organismo.

densan y resumen en la transición desde el «institutional approach» vigente hasta los años '80, al "grant approach», que se viene consolidando desde entonces ${ }^{1}$. El Centro Público de Investigación (CPI, en lo sucesivo) ha dejado de ser la unidad básica de la financiación pública de la ciencia. El Estado ya no entrega dinero en forma discrecional e incondicionada a universidades y OPI para que estos, internamente, lo gestionen y emplacen en aquellas líneas de investigación y con aquellos fines que la comunidad científica

1. Estos dos conceptos provienen de Stephan (1996). priorice. Las condiciones que así se propiciaron de "elevada autonomía de los académicos y el elevado nivel de autogobierno dentro de las universidades" (Friesike y Schildhauer, 2014), quedaron dinamitadas con la llegada del "grant approach». Ahora es el proyecto de investigación la unidad básica de financiación de la investigación. Y las trasferencias directas del Estado a los centros de investigación, en franca mengua, cada vez se hallan más condicionadas al cumplimiento de determinados objetivos, como número de patentes generadas, publicaciones científicas en revistas de alto impacto, volumen de financiación externa lograda vía con- 
vocatorias competitivas de investigación, etcétera.

Este desplazamiento del foco desde la institución científica como tal al proyecto de investigación, a los resultados del trabajo científico, parece un cambio sutil, pero sus implicaciones son muchas, y de la mayor trascendencia. Ahondaremos en el tema más adelante. Por de pronto, cabe comentar que el "grant approach" tiene origen, y sólo puede tener origen, en la más estricta separación entre «agentes de financiación», de un lado, y «agentes de ejecución», del otro; distinción que recorre y atraviesa de arriba abajo el conjunto de los SNCyT, y que modifica por completo la diferenciación formal convencional de la política científica, establecida entre el sector público y el sector privado. La consecuencia práctica de esta disociación es que, a diferencia de lo que fuese común en los SNCyT hasta los años '80 del pasado siglo, las transferencias cruzadas entre los ámbitos público y privado son posibles y habituales. Así, hay entidades públicas, como las universidades, que ejecutan investigación sufragada por las empresas. Y, viceversa, empresas cuyas actividades en $I+D$ reciben financiación del Estado, bien a título individual, o bien en consorcio con otras instituciones. Son las transferencias cruzadas el segundo elemento a considerar respecto de las nuevas directrices de la política científica pública.

Pero todavía existe una tercera característica decisiva, a saber, el incremento de las relaciones entre CPI y empresas y su incidencia creciente en los presupuestos de los primeros. Sin embargo, no hay mucho más que esta circunstancia pueda decirnos respecto del fenómeno que aquí nos ocupa, por cuanto que la necesidad de estos vínculos ya estaba portada por la separación entre «agentes de ejecución» y "agentes de financiación», y las transferencias cruzadas público - privadas que de ella se derivan. La absoluta indiferencia para los Centros Públicos de Investigación respecto del origen de los fondos con los que se sufraga la investigación, comporta que sus relaciones con la empresa no constituyan sino un medio más, tan adecuado como la captación de subvenciones en convocatorias públicas, para proseguir con el desarrollo de su actividad productiva.

Éste es, grosso modo, el concreto al cual se enfrenta la investigación, y de cuya necesidad ha de dar cuenta. Agotado el análisis por esta vía, el siguiente epígrafe del trabajo indaga en las principales conclusiones extraídas por Rosa Luxemburgo de su estudio de la acumulación capitalista; lecciones teóricas y políticas que consideramos indispensables para aprehender las leyes que rigen el fenómeno en liza $y$, subsecuentemente, organizar nuestra propia acción respecto del mismo.

\section{Conocimiento como reconocimiento. La acumulación del capital en Rosa Luxemburgo}

La necesidad de escribir La acumulación del capital se la dictó a Rosa Luxemburgo su labor como profesora de Economía Política en la escuela del Partido Socialdemócrata Alemán (SPD, por sus siglas en alemán). Según ella misma manifestó, había encontrado grandes dificultades para explicar satisfactoriamente el proceso de acumulación capitalista; y, a su juicio, los controvertidos esquemas de la reproducción que Marx elaborase para el 
segundo libro de El Capital, resultaban del todo insuficientes. Emprendió entonces la tarea de investigar las formas históricamente concretas que adopta el proceso de reproducción ampliada del capital social total; ocupación esta que, a la sazón, resultaría en una de sus más reseñables contribuciones al avance de la teoría marxiana.

Para Rosa Luxemburgo, son dos los problemas que presentan los esquemas de la reproducción ampliada del libro segundo de El Capital, y que los hacen incapaces de dar cuenta del proceso de acumulación capitalista. Por un lado, en ellos no se puede encontrar el origen de la demanda suplementaria que ha de realizar la plusvalía adicional. Por el otro, los esquemas no son consecuentes con las propias leyes del capital desentrañadas por el propio Marx con carácter previo. Así, mantienen ciclo tras ciclo la misma tasa de explotación y la misma proporción de plusvalía destinada a la capitalización, es decir, la misma distribución de la masa de plusvalía entre consumo capitalista y extensión de la producción; lo que equivale, a la postre, a una composición orgánica del capital invariable 2 . Esto da lugar a

2. De hecho, Luxemburgo explica que los supuestos del esquema de la reproducción ampliada frustran cualquier mejora ulterior en la composición técnica del capital, por cuanto que la forma material que ha de adoptar la plusvalía destinada a capitalización está perfectamente determinada de antemano, y que las diversas secciones sólo pueden obtener sus diversos elementos de producción por cambio mutuo. Esto, que es sistemáticamente pasado por alto por los críticos de la revolucionaria polaca, comporta que la técnica de la producción actual prescribe la técnica de la reproducción ampliada futura. La plusvalía en medios de vida de la sección II no puede, conforme a su propia naturaleza material, convertirse en medio de producción para la reproducción ampliada de la sección I. Por consiguiente, la resultados sorprendentes. El más notable que comenta la revolucionaria polaca es que el sector de medios de vida no logra acumular al mismo ritmo al que lo hace el sector de medios de producción, sino que la reproducción ampliada de aquel se supedita por completo a la de este, al punto de que hay años en los que no acumula en absoluto. Luxemburgo concluye que todas estas deficiencias en la exposición resultan de que se trabaja en ellos con la abstracción teórica que atraviesa todo $E /$ Capital, a saber, la de una sociedad capitalista compuesta en exclusiva por obreros y capitalistas. Ésta permite ilustrar a la perfección el proceso de reproducción simple y salir al paso de la falsa concepción, con origen en Adam Smith, de que todo el producto social anual se resuelve en salarios y renta (Luxemburgo, 1975); sin embargo, no alcanza para enfocar el verdadero problema de la acumulación del capital, a saber, la realización de la plusvalía.

Ésta es la segunda idea central de La acumulación del capital. A diferencia de los teóricos marxistas de la época, Luxemburgo consideraba que la realización de la plusvalía era un problema de primer orden que el capital tenía que hacer frente en el curso de su acumulación. Y ello en tanto que la "angosta base sobre la que descansa las condiciones del consumo social" (Marx, 2000) se contrapone inmediatamente a las enormes capacidades productivas desarrolladas por el capital $^{3}$. Esta contradicción interna tiene

sección I de la producción no puede crecer más rápidamente que la sección II, como prescribe el mismo progreso de la productividad del trabajo y como sucede en la realidad.

3. Uno de los más agudos críticos de la teoría de la acumulación de Rosa Luxemburgo, Paul Mattick, da un curioso argumento para desechar 
que compensarse con una ampliación constante del "campo exterior de la producción”, con el mercado. Y, según lo entiende Rosa Luxemburgo, se trata de una ampliación por encima de capitalistas y obreros mismos.

Para Luxemburgo, la necesidad de expandir el campo exterior de la producción para resolver las contradicciones internas a la producción capitalista toma forma concreta en la política colonialista e imperialista de las potencias capitalistas. El plusproducto excedente se realiza manu militari, y, así, la relación social capitalista se despliega en y a través del «medioambiente precapitalista» (denominación dada por Luxemburgo, 1975), conquistando y disolviendo las formas de producción pretéritas. Al mismo tiempo que crea a los adquirientes de las mercancías para el capital, la política imperialista arranca de estos modos de producción atávicos sus recursos productivos, incluyendo a la fuerza de trabajo misma. La política imperialista pone de manifiesto que la escala material de la producción es el mundo entero: el capital recorre el globo, de extremo a extremo, para someter todas las fuerzas productivas en él contenidas a la lógica de la valorización del valor. "La acción política no es sino vehículo

que el carácter antagónico de la distribución del producto del trabajo social en el capitalismo sea fuente de contradicciones insalvables. Para él, el "subconsumo" de las masas es fenómeno común a todas las formas de producción en las que impera la propiedad privada y la división en clases (Mattick, 1977). Niega con ello la differentia specifica que la anarquía de la producción, o sea, el carácter de privado e independiente con el que se realiza el trabajo social bajo la forma capitalista, confiere a la organización del proceso metabólico social, que incluye tanto la producción como el consumo. del proceso económico", como la propia Luxemburgo sentenciara.

Pero la contribución del Estado capitalista a la acumulación del capital no sólo consiste en el ejercicio de la violencia física directa. El segundo momento que integra la unidad material de la acción estatal, aun en la forma históricamente limitada en que Luxemburgo la analizase, como militarismo, es la ejecución de su poder de compra, de la demanda solvente del Estado capitalista. A este consagra la autora todo el último capítulo de La acumulación del capital (Luxemburgo, 1975). Al decir de Luxemburgo, la demanda del Estado capitalista crea un mercado completamente nuevo al capital, el de los artilugios de guerra. Éste queda fuera tanto del sector de medios de producción como del sector de medios de vida de la producción social, y su crecimiento, por cuanto que es el mismo Estado quien realiza la plusvalía, no conoce más límite que la misma acumulación del capital. La transferencia de capital a esta nueva esfera de la producción es posible en virtud del sistema de impuestos indirectos, aquellos que gravan el consumo y sobre los que, según argüía Marx, "gira todo el sistema tributario moderno" (Marx, 2000). Los impuestos indirectos establecen un reparto del producto del trabajo social entre capital y trabajo ex post, es decir, después del intercambio que entre ambos se establece antes del proceso de trabajo. Su efecto inmediato es una mengua en la participación de los trabajadores en el producto social, esto es, una reducción de su salario real. Se libera así una parte del capital variable de la sociedad, una parte del capital social total que se destinaba a la producción de medios de vida, sin que haya merma en el volumen de plus- 
valía extraída ${ }^{4}$. El dinero ahora ocioso se encuentra en manos del Estado; ésta es la fuente de su poder de compra. Los medios de producción igualmente liberados pueden movilizarse para la satisfacción de las necesidades de este nuevo cliente; necesidades que, según Rosa Luxemburgo, se orientan fundamentalmente hacia la obtención de pertrechos bélicos de todo tipo.

Lo relevante para el caso que nos ocupa de la exposición de la revolucionaria polaca, es que ella identifica correctamente que la acción estatal es mediación necesaria para el despliegue y reproducción ampliada de la relación social capitalista. Y ello, tanto en su momento de violencia física directa, que toma forma históricamente concreta en la política imperialista, como en su momento de ejercicio de poder de compra. A tal respecto, su contribución constituye un desarrollo más concreto de las determinaciones generales del Estado capitalista avanzadas por el propio Marx en El Capital (véase Starosta y Caligaris, 2017, cap. 5); y, como tal, una contribución de primer orden para comprender las potencias y límites de nuestra propia acción respecto del representante político de la burguesía. Pero no sólo. Más adelante, recuperaremos las lecciones de Luxemburgo al respecto para poner en solfa el papel desempeñado por la acción estatal en la transformación de las formas sociales de la producción científica.

4. Que el salario real disminuya nada tiene que hacer con los niveles de explotación del trabajador en base a una composición técnica del capital dada. Habiendo de adelantar una cantidad inferior de capital variable, el capital obtiene exactamente la misma masa de plusvalía, pues el grado de explotación permanece inalterable. La repercusión del menor salario real sobre la reproducción de la fuerza de trabajo, apunta Luxemburgo, sólo se verifica en el muy largo plazo.

\section{3.l. La expansión del capital a través del «medioambiente precapitalista»}

Varios capítulos de la tercera parte de La acumulación del capital, están consagrados a desgranar las diversas situaciones que el capital ha tenido que enfrentar en su despliegue histórico. Ilustra la autora de la obra, así, que la relación social capitalista "no flota en el vacío", y que la ampliación del campo exterior de la producción (el mercado) requiere de la más completa transformación de los modos de organización del trabajo social que imperan allende las fronteras de los países capitalistas. Luxemburgo identifica en su análisis tres formas concretas que adopta la expansión de la relación social capitalista en y a través de su «medioambiente precapitalista», a saber: lucha contra el comunismo primitivo; lucha contra la economía campesina e introducción de la economía mercantil propiamente dicha; y, finalmente, lucha contra la pequeña producción. Comentemos brevemente cada una de estas situaciones.

\section{1.l. Comunismo primitivo u originario}

La economía natural fue la forma predominante de organización social de la producción durante milenios, desde los orígenes mismos de la vida comunitaria. Así, su huella puede seguirse hasta llegar a los estadios más primitivos del desarrollo de la productividad del trabajo social, entre los pueblos nómadas dedicados a la caza; y de un extremo a otro del globo, desde las comunidades germánicas hasta los incas, y desde las más remotas montañas del actual Afganistán hasta la vida aborigen de Australia (Luxemburgo, 1974). 
En las formas de organización de la vida social que reciben el nombre de comunismo primitivo, todos los medios de producción están férreamente uncidos a la comunidad, y no se conoce la propiedad privada sobre estos. La tierra y todo lo que en ella se contiene pertenece a la colectividad (generalmente, organizada en forma de clanes y tribus, es decir, por vínculos filiales), y el proceso de metabolismo social se organiza consiguientemente de forma colectiva. Nadie puede reclamar propiedad alguna sobre los medios de producción. Incluso en aquellas formas concretas de economía comunista donde las unidades familiares explotan parcelas delimitadas de tierra, tal derecho viene concedido por sus vínculos con la comunidad (Luxemburgo, 1975; Marx, 2005), y no es inhabitual que éstas se repartan cada cierto tiempo mediante sorteo (Luxemburgo, 1974).

Dicho de una vez, la característica diferencial de las formas de economía natural es que se produce en comunidad y se consume en comunidad los productos del trabajo social, siempre con arreglo a un plan colectivo establecido de antemano; es decir, sin mediación de la forma mercantil, como trabajo directamente social. No existe separación de los trabajadores respecto de sus medios de trabajo; los hombres se relacionan con el medio que les rodea como con "su propia naturaleza inorgánica” (Marx, 2005).

\subsubsection{Economía campesina e intro- ducción del intercambio mercantil}

En la economía campesina, la familia campesina constituye la unidad básica de la producción social. La familia campesina — de base más reducida que la tribu o gens - es autosuficiente. Aun teniendo por actividad principal la agricultura o la ganadería, toda la industria auxiliar se desarrolla al interior de esta misma unidad, en base a una estricta división del trabajo. En la familia campesina se concentran todas las fuerzas productivas del trabajo social en este estadio de su desarrollo.

Las relaciones sociales de producción de la economía campesina están determinadas por la propiedad privada sobre la tierra y el resto de medios de producción empleados por la unidad familiar. Pero ello no desdibuja el carácter natural que presenta esta forma social de organización del metabolismo social, por cuanto que aquella posesión privada de los medios de producción sigue teniendo por fin el sustento y el goce propios, y no el enriquecimiento. La familia produce estrictamente para su propia reproducción; sólo en épocas de cosecha particularmente buenas, su trabajo genera un excedente que no puede ser consumido y que, consiguientemente, se destina al intercambio. A la sazón, el metabolismo social basado en el cambio de mercancías, clave de bóveda del modo de producción capitalista, presenta aquí un carácter limitado, irregular y fortuito. El obstáculo que el capital encuentra aquí no es, por consiguiente, la propiedad colectiva de los medios de producción, como en los estadios de desarrollo pretéritos, sino la producción autosubsistente con base en la propiedad privada.

La apertura al mercado mundial de aquellos países en los que impera este modo de producción, pasa por poner al campesino en la necesidad del cambio permanente, de que el producto completo de su trabajo, y no sólo el excedente, se destine al mercado. Según Luxemburgo, el cobro de tributos en dinero, y no en especie, es el medio concreto por el que se somete al campesino al intercambio y a 
la ley del valor, en tanto que constantemente ha de vender lo que produce para obtener medios de pago con los que atender las exigencias del fisco (Luxemburgo, 1974). Asimismo, el proceso metabólico social basado en el intercambio mercantil se acelera con la extensión de líneas férreas y grandes obras de infraestructura por todo el territorio, que los capitales europeos desarrollaron con cargo a los erarios nacionales (en Luxemburgo, 1975, se aportan datos de gran interés respecto del caso turco). Por mor de la separación así lograda de la industria doméstica respecto de la agricultura y la ganadería, se produce un desarrollo unilateral del trabajo hacia el valor de cambio en su doble determinación, formalmente, como producción para el intercambio (valor de cambio como único valor de uso de las mercancías que el campesino produce), y materialmente, en tanto que valor de uso para otros (Marx, 2005/1971).

\subsubsection{Pequeña producción capitalista}

Con la disolución de la economía campesina, la separación de agricultura e industria, y la introducción por la fuerza del intercambio mercantil, nos encontramos ya en la antesala de la producción capitalista desarrollada. Pero aún queda una última puerta que franquear, a saber, convertir a la fuerza de trabajo en objeto de compraventa. Y esto es sólo posible en tanto que el pequeño productor quede "liberado" de sus medios de producción y de las relaciones de dependencia personal que estos pudiesen traer aparejadas. La ruina de la pequeña explotación se impone a través de la competencia entre capitales. El pequeño productor, con sus medios de producción limitados y su muy exiguo capital, se muestra impotente ante la gran fábrica capitalista, ante la concentración en masas descomunales de los medios de producción y de la misma fuerza de trabajo. En La acumulación del capital, Luxemburgo (1975) toma el caso de la producción triguera en Estados Unidos para ilustrar tal dinámica. Más generalmente, la producción capitalista absorbe y subsume a sí misma, una tras otra, todas las esferas de la producción social que antes él mismo ha desgajado de su unidad primigenia (economía natural) ${ }^{5}$, consagrando con ello la absoluta separación del trabajador respecto de sus medios de trabajo. Convertido aquel en mero obrero asalariado, su sustento depende de la venta reiterada de su fuerza de trabajo, única mercancía de la que es poseedor. Y aquel intercambio sólo se verifica en tanto que el trabajador está en condiciones de aportar al capitalista un excedente por sobre sus propios medios de vida; sólo en tanto que produce plusvalía, fin y motivo impulsor de la producción capitalista.

\section{La subsunción de la «ciencia pública» al capital}

Luxemburgo asume en su análisis de la reproducción social ampliada y del militarismo, que la relación social capitalista se expande hacia afuera de los mismos países capitalistas; que el «medioambiente precapitalista» se sitúa geográficamente allende las fronteras de las grandes potencias capitalistas de su época (fundamentalmente, Europa y Estados Unidos). Pero lo cierto es que formas pretéritas de

5. Porque, como dice Marx en varias de sus obras, incluyendo El Capital (Marx, 2000), "la división del trabajo puede existir sin intercambio, pero el intercambio no puede existir sin división del trabajo". 
producción social pueden encontrarse al interior de las mismas naciones dominadas por la organización social capitalista, como la misma autora consigna en varios pasos de su obra. De hecho, el contradictorio movimiento expansivo del capital, en su forma de acumulación, también se da hacia dentro de los países capitalistas, sometiendo a la lógica de la valorización del valor todas aquellas esferas de la producción social aún no formalmente subsumidas. Aquí, de nuevo, la acción del Estado media en el despliegue de la relación social capitalista, tanto bajo la forma de violencia como bajo la forma de ejercicio de poder de compra. Tal es el caso de la producción científica.

Los cambios en la estructura económica de la investigación consignados sucintamente en \$2 no se explican sino por mor de la necesidad que tiene el capital de conquistar la esfera de la producción científica y extraer de ella toda la plusvalía posible. Tanto el retroceso del gasto público en I+D como las mismas modificaciones en las políticas públicas de asignación y emplazamiento de recursos para investigación, son simultáneamente causa inmediata y evidencia histórica de la progresiva disolución de las formas de producción imperantes en la ciencia con carácter previo a la irrupción del capital. Ahora bien, ¿cuáles son estas formas sociales de producción?

\section{I. La ciencia como «economía natural»}

Sólo el más amplio desarrollo de la producción capitalista, posibilita la existencia como esfera independiente de la producción, como rama diferenciada de la división del trabajo social, la producción

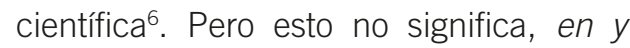
de por sí, que la ciencia sea producción capitalista. Marx (2005) afirmaba que el sistema entero de la producción capitalista había de estar presupuesto para que emerja a la superficie el valor de cambio, como simple punto de partida de la producción. Aún tras la II Guerra Mundial, la actividad académica se encontraba lejos de alcanzar semejante condición. De hecho, sólo en fechas recientes puede considerarse que, con carácter general, el valor de cambio constituye punto de inicio y perpetuum mobile de la investigación.

Esto mismo puede analizarse desde otra perspectiva, atendiendo a la naturaleza mercantil de los productos del trabajo bajo el modo de producción capitalista. Según cita Rosdolski (1978) de Teorías de la plusvalía, para Marx, la forma plenamente desarrollada de la producción mercantil requiere la concurrencia de dos factores:

a) Los factores de la producción (materia prima, instrumentos de producción y, también, la fuerza de trabajo) entran en el proceso laboral como mercancías, valores de uso enajenados a través del intercambio.

6. Marx hacía notar en El Capital, que la producción de ingenios e inventos de todo tipo con aplicación en la fabricación industrial, sólo hacia la segunda mitad del siglo XIX, luego de casi dos siglos de producción capitalista, había comenzado a separarse netamente como esfera diferenciada del trabajo social. La actividad científica propiamente dicha habrá de aguardar aún unas cuantas décadas más para constituirse como rama específica de la producción. La propuesta de Humboldt (2005) de que las universidades aúnen investigación y enseñanza, puede tomarse como una primera manifestación en el pensamiento de tal necesidad. 
b) El producto del proceso de trabajo no tiene por más fin que el intercambio; se produce con vistas al intercambio. Bajo la égida de la producción capitalista, el producto particular del trabajo privado e independiente, tiene a su carácter cambiable por todo valor de uso para su mismo productor.

Ciertamente, la primera de estas condiciones estaba dada en el caso de la actividad científica hacia los años '60 y '70 del siglo pasado; pero no así la segunda. La forma mercantil de los productos del trabajo científico no se encontraba por entonces en el centro mismo de la actividad laboral académica. Ésta aparecía, más bien, en sus márgenes, en aquellos espacios de metabolismo con otras esferas del trabajo social; o, asimismo, en sus intersticios, en forma de revistas académicas propiedad de empresas editoriales tales como Springer, Sage u otras. Pero, así como el intercambio puntual con otros grupos no distorsionaba en absoluto las formas de organización social del trabajo en las comunidades comunistas primitivas, así la repercusión que en el conjunto de la actividad académica tienen aquellas formas mercantiles es nula; su presencia no alteraba, ni poco ni mucho, el carácter históricamente específico de la producción científica.

La correspondencia entre el comunismo primitivo y los modos tradicionales de organización social del trabajo científico aún puede llevarse más lejos. Aquí, como allí, la producción se orienta exclusivamente hacia la satisfacción de las necesidades humanas; la actividad laboral no conoce más fin que el de crear valores de uso, bienes útiles a la comunidad. En ambos casos, es la comunidad, en las más disímiles formas en que ésta pueda estruc- turarse, la que organiza internamente su proceso de trabajo, con arreglo a sus mismas necesidades, esto es, en conformidad con un plan propio de trabajo. La realización de las libertades investigadora y de cátedra debe de interpretarse, a la sazón, como evidencia prístina de este carácter históricamente específico de las relaciones sociales de producción al interior de la ciencia; su reivindicación contemporánea, al contrario, como el signo de la completa disolución de aquellas ${ }^{7}$.

Dicho de una vez: por cuanto que en la ciencia se producía y consumía en comunidad, estábamos en presencia de una forma transmutada de comunismo primitivo. Y nadie supo captar mejor esta condición específica de la institución académica que el sociólogo de la ciencia norteamericano Robert K. Merton, cuyo descubrimiento resulta aún más meritorio y loable por haber sido realizado de manera puramente casual, buscando argumentar una cuestión completamente diferente, y sin haber sido consciente durante toda su vida de la naturaleza del hallazgo con el que hiciera época en su campo.

Merton estableció que el "comunismo» era uno de los cuatro grandes principios normativos de la actividad científica, del «ethos científico» (Merton, 1985). Así, dice el autor que "los hallazgos de la ciencia son un producto de la colaboración social y son asignados a la comunidad. Constituyen una herencia común en la

7. Los que revisten de un carácter progresista la reivindicación de «fiscalización social» de la ciencia, olvidan deliberadamente que el ser social está determinado por el carácter enajenado en el capital de las fuerzas productivas. Los que, al contrario, claman por un retorno a la libertad académica, no paran mientes en que ésta no fue sino producto histórico de un desarrollo insuficiente de la productividad del trabajo científico. 
cual el derecho del productor individual es severamente limitado" (Merton, 1985). En esta definición encontramos notas de sabor que recuerdan al análisis hecho por Marx a colación de aquellas comunidades en las que impera el comunismo primitivo (Marx, 2005); y también a aquel planteado por Luxemburgo tanto en La acumulación del capital como en Introducción a la Economía Política. El nexo de unión está dado por el hecho de que aquí, como allí, el trabajo individual está puesto por la comunidad, es trabajo directamente social; su producto es producto de disfrute colectivo, y colectivamente distribuido entre todos los miembros de la comunidad; y al trabajador sólo se le entrega la parte del producto social total que le corresponda en virtud de aquellas relaciones naturales (Marx, 2005). Puesto que el suyo no era un trabajo privado, de él no podía reclamar más de lo que previamente estuviese determinado. Tal ley debe de imperar, a juicio de Merton, también en la comunidad científica: "[e]l carácter comunal de la ciencia se refleja, además, en el reconocimiento por los científicos de su dependencia respecto a una herencia cultural de la que no reclaman una parte especial" (Merton, 1985). Puesto que la apropiación se da en colectividad, las actividades particulares son mutuamente dependientes, pero ningún individuo puede apropiarse motu proprio de esa "herencia cultural" (léase, trabajo objetivado), ni reclamar de ella más de lo que la comunidad dictamina.

Recapitulamos: trabajo organizado al interior de la comunidad científica, trabajo directamente social; distribución por parte de la comunidad de los productos de este trabajo social, delimitando estrictamente, así, la apropiación privada de los mismos por parte de cada miembro individual. En la época en que el sociólogo norteamericano escribía esto - la publicación original data de 1941 - , los científicos traban entre sí y para con sus condiciones laborales relaciones de producción que son propias de una economía en la que impera el comunismo originario, en la que la producción se desarrolla en conformidad con un plan predeterminado (y que se fija mediante sistemas de normas, más o menos ritualizadas y sublimadas en sistemas de culto; es decir, en un determinado «ethos»), por y para la satisfacción de las necesidades de la vida comunitaria misma.

Todavía es posible encontrar hoy en día trazas de esta forma social de organización del trabajo científico, pese a hallarse en proceso de disolución acelerada. De hecho, son éstas harto evidentes; lo que ocurre es que muy rara vez se las considera en esta determinación. Hablamos del sistema de revisión por pares, de un lado, y de la férrea jerarquía social al interior de las instituciones científicas, por el otro. Ambos constituyen dos momentos esenciales del proceso de organización del trabajo social científico bajo las relaciones de producción propias del comunismo primitivo; y siguen su jugando su papel en la organización contemporánea de la actividad académica, aunque en forma progresivamente atenuada y sometidos a poderosas tensiones que evidencian su misma condición caduca.

8. En el caso del sistema de revisión por pares, esto se revela con particular vehemencia. El mayor volumen de producción de artículos científicos, sumado a las nuevas posibilidades de publicación y diseminación de los resultados de investigación que Internet y las tecnologías digitales auspician, han hecho saltar por los aires el peer-reviewing tal y como se ha practicado históricamente, entre acusaciones de lentitud, ineficacia, inepcia en las valoraciones, y sesgos, deliberados o no, hacia determinados paradigmas 
Mediante la revisión por pares, la comunidad somete a evaluación la calidad del trabajo desarrollado por cada uno de sus miembros individuales. Todo producto ha de cumplir unos criterios mínimos indispensables para que resulte de utilidad a la colectividad; en caso de no satisfacerlos, habrá de ser desechado por inútil. En la jerarquía científica, encontramos plasmación del complejo proceso de organización del trabajo científico, y en el que cada miembro particular ocupa una posición específica respecto del organismo vivo en su conjunto.

\subsection{Lucha contra el comunismo científico}

Como vimos arriba, el despliegue de la relación social capitalista requiere, como conditio sine qua non, de la disolución de las formas sociales de producción propias

teóricos, metodologías o tipo de resultados. Pero la cosa no queda aquí. El denominado «open peer review» está comenzando a hacer época, y hasta autoridades públicas con competencias en materia de política científica, como la Comisión Europea, comienzan a darle entrada en sus normas y disposiciones (véase Comisión Europea, 2016). En esencia, el «open peer review» pretende suplantar el juicio experto de un reducido grupo de académicos por la evaluación colectiva tanto de expertos como de no expertos. Pero la calidad intrínseca de la publicación no se dirime en el contraste de los juicios de valor emitidos por cada revisor particular, sino que se establece indirectamente, a través de su formalización en protocolos y sistemas de medida, es decir, en métricas. Así, los registros obtenidos en ciertos marcadores por un producto científico cualquier, como el número de veces en que se ha consultado, el número de veces que su contenido se comparte en redes sociales, etcétera, pasan a constituirse en criterio decisivo a la hora de determinar sus propiedades inherentes y, por tanto, su utilidad. de la economía natural que imperan en el «medioambiente precapitalista» (Luxemburgo, 1975). El capital corta los lazos que uncen las fuerzas productivas a las comunidades primitivas, para apropiarse de aquellas y conformar, al mismo tiempo, una nueva demanda solvente que realizará su plusproducto. La subversión de los modos de organización social pretéritos, la incorporación de los territorios más alejados y de las comunidades más primitivas al entrelazamiento metabólico general en forma de intercambio mundial, pasaba indefectiblemente por la separación del trabajador respecto de sus condiciones de trabajo. El capital, simplemente, no puede aguardar a que se agudicen las contradicciones internas de las formas históricas de producción que lo circundan, al punto de que su misma reproducción se vuelva insostenible. Él mismo ejerce como factor de disolución al desgajar la unidad orgánica material del productor y sus medios de producción, ora a través de la violencia estatal, ora a través del intercambio pacífico (Luxemburgo, 1975).

Misma dinámica histórica recapitula el curso de la actividad académica en el último medio siglo. Ante el despliegue de la relación social capitalista, el modo de organización del trabajo científico tradicional colapsa y se hunde. De nuevo, el apetito insaciable de plusvalía del capital. De nuevo, la acción estatal como enzima catalizadora del proceso económico. Una vez más, el desarrollo unilateral del trabajo hacia el valor de cambio, y el ulterior desgajamiento de la unidad orgánica entre el trabajador y sus condiciones laborales. Bajo la luz que irradia el análisis planteado por Luxemburgo acerca del movimiento contradictorio del capital en su reproducción ampliada, podemos identificar el contenido inmanente de los 
cambios en la estructura económica de la ciencia comentados en $\S 2$.

La reducción en el gasto público destinado a I+D es el primer paso en dirección a quebrar por la base las relaciones sociales de producción imperantes en la esfera científica. Unos rápidos cálculos a partir de las estadísticas de la OCDE, demuestran que la inversión privada ha crecido desde 1981 más lentamente de lo que ha caído el gasto público; o lo que tanto vale decir, que el predominio actual del gasto empresarial en ciencia no es tanto fruto de su propio avance como del retroceso en la dotación presupuestaria a universidades y otros centros de investigación por parte de los estados. Desde el periodo de posguerra, y aun con anterioridad, el Estado capitalista era el que sufragaba profusamente la actividad científica; y lo hacía confiriendo amplia autonomía a la propia comunidad para la organización interna de sus procesos de trabajo. Por tanto, el simple hecho de que las autoridades públicas reduzcan el gasto en I+D supone para estas comunidades un problema de primer orden. Pero el mero recorte en los presupuestos públicos en materia de ciencia no es, de por sí, suficiente para transformar de arriba abajo las formas sociales de la producción científica. Ello se explica por el sencillo motivo de que, al reducir la base material sobre la que se asienta la comunidad científica, ésta continuará reproduciéndose exactamente en las mismas condiciones, sólo que con un tamaño menguado? .

9. Hay que puntualizar, además, que existe un límite inferior perfectamente determinado a la dotación presupuestaria de $\mathrm{I}+\mathrm{D}$, cuyo rebasamiento pondría en entredicho la misma reproducción social de la sociedad enajenada en el capital. El mayor desarrollo de las fuerzas productivas impulsa constantemente tal límite hacia arriba. Cuanto
Las reducciones presupuestarias por parte del erario constituyen el prerrequisito indispensable para separar a los productores científicos de sus condiciones laborales y obligarlos a intercambiar los productos de su trabajo. Aunque la necesidad del cambio como forma del proceso metabólico está dada en este punto simplemente como potencia. La actualización de tal potencia, su realización, requiere de la mediación de la acción estatal; en este caso, en forma de actuación legislativa y política científica pública. Los cambios en la dotación presupuestaria a la I+D por parte de los estados - también comentados en \$2- dan curso a la indefectible separación del trabajo científico respecto de sus medios de producción, convirtiendo a las instituciones científicas públicas en unidades de producción formalmente independientes entre sí y respecto del Estado; esto es, en productores privados e independientes que sólo pueden participar del proceso metabólico social de un modo indirecto, a través del atributo social del cambio que portan los productos de su trabajo.

\subsection{Desarrollo unilateral del trabajo científico hacia el valor de cambio}

Al retornar sintéticamente hacia lo cambios introducidos en la política científica pública, el análisis pone en relieve que su orientación general no es sino la de transformar los Centros Públicos de

más se ha valorizado el valor, cuanta más plusvalía ha sido acumulada, tanta menos plusvalía adicional se puede extraer del trabajo vivo mediante el desarrollo de la productividad del trabajo que el conocimiento científico auspicia (nueva maquinaria, mejoras técnicas y tecnológicas en el proceso inmediato de producción, etcétera). 
Investigación (universidades y OPI) en unidades de producción formalmente independientes del Estado; esto es, cuya financiación no depende en absoluto de las transferencias directas, discrecionales e incondicionadas hechas por los organismos públicos. La libertad y autonomía de las que gozaba la comunidad científica para organizar colectivamente su trabajo, al auspicio de la ingente dotación presupuestaria estatal a los loci de la «ciencia pública»; es ahora la libertad e independencia que el carácter de privado con el que se ejecuta el trabajo confiere a un abigarrado grupo de centros de investigación. La forma mercantil de los productos del trabajo científico hace finalmente acto de presencia. Las relaciones de dependencia personal pretéritas truecan en la dependencia impersonal respecto de las potencias del mercado.

Cualquier organismo público de investigación tiene ahora por exigencia ineludible el vender la totalidad de los resultados de investigación obtenidos, los frutos de su propio trabajo, cualquiera que sea la forma material que estos adopten. Poco queda ya de la antigua comunidad científica, cuya producción se destinaba por completo a la satisfacción de las necesidades propias. Hoy en día, la forma mercantil de los resultados de investigación determina por completo el proceso de metabolismo social al interior de la esfera académica; se produce para vender, y a la venta sigue inmediatamente la compra, la retroconversión del dinero en los medios de producción necesarios para proseguir con la actividad investigadora. Para el conjunto de los productores de conocimiento científico, el producto de su trabajo no posee más valor de uso que su carácter cambiable, que el valor que porta.
La separación y ajenidad del productor respecto de sus medios de trabajo no queda consumada a esta altura, sin embargo. Por de pronto, la acción estatal vista hasta aquí, sólo ha puesto esta disociación. Pero, del mismo modo que el resultado del proceso inmediato de producción comandado por el capital, no es sólo la mercancía, sino la relación social establecida entre capitalista y obrero, entre trabajo asalariado y capital; así el curso mismo de la producción de conocimiento científico bajo esta nueva forma de organización social renueva constantemente el desgajamiento del trabajador de las condiciones en las que despliega su trabajo. Para conocer cómo se reproduce esta separación, hay que avanzar hasta las formas más concretas en que se produce el metabolismo social en base a su carácter mercantil.

La disociación entre "agentes de financiación» y «agentes de ejecución» que atraviesa y modifica substancialmente toda la estructura económica de la ciencia contemporánea, es la forma concreta en que aquí se materializa la separación del trabajo presente respecto del trabajo pretérito. El trabajo científico se encuentra a un lado, como «agente de ejecución»; los medios de trabajo, fundamentalmente en forma dineraria, en otro, como «agente de financiación». Para que el proceso metabólico social general no cese y siga contando con un flujo sostenido y suficiente de conocimiento científicamente sancionado (y de tecnología en que aquel se objetiva), es indispensable que ambos sujetos entren en relación. Pero la única relación de la que son capaces es el intercambio mercantil, libres como están de todo vínculo personal entre sí o con respecto a terceros. Son los productos de sus respectivos trabajos privados 
e independientes los que portan la relación social aquí presente, la capacidad de cambiarse recíprocamente en tanto que equivalentes. La conciencia y voluntad de los sujetos se encuentra al servicio de una potencia social ajena y que pertenece a la mercancía; actúan, por consiguiente, como personificaciones de la mercancía (Íñigo Carrera, 2007; Marx, 2000).

Lo anterior comporta que, uno frente al otro, los sujetos involucrados en el cambio - en nuestro caso, «agente de ejecución» y «agente de financiación»- han de reconocerse mutuamente como poseedores, como propietarios de sus respectivas mercancías. Con ello basta y sobra. A la sazón, a cada uno de ellos le resulta completamente indiferente quién tenga delante, quién posee la mercancía por la que cambia la suya propia. Para la universidad u Organismo Público de Investigación que ejecuta el trabajo académico, resulta completamente fortuito que el dinero provenga de una empresa privada o de una administración pública. Las transferencias cruzadas entre los sectores públicos y privados de los SNCyT contemporáneos se presentan, entonces, como causa inmediata y resultado siempre renovado de la separación del trabajador científico respecto de sus condiciones laborales.

Pero lo cierto es que ese carácter indiferente y fortuito constituye tan sólo una potencia inmanente. En su exteriorización, encontramos tendencias de intercambio entre agentes particulares de los SNCyT bien definidas. La Tabla 2 recoge datos sobre el volumen y el porcentaje de dinero público y privado ejecutado en 2015 en las universidades de cuatro países que destacan, precisamente, por sus elevados índices de inversión privada global en I+D. Llama la atención que incluso allí donde los capitales individuales son más intensivos en conocimiento, la proporción en que estos sufragan la investigación académica oscila entre lo moderado y lo despreciable.

El Estado sigue siendo, con mucho, el agente financiador por excelencia de la investigación desarrollada en los Centros Públicos de Investigación. Lo que significa, expresado en términos sucintos, que es el principal adquiriente o demandante de los resultados de investigación obtenidos en tales instituciones. Por más 'público' que el centro de investigación en cuestión sea o se reivindique, la naturaleza de la relación que establece para con el Estado no se diferencia un ápice de aquella que podría entablar con cualquier otro ente financiador, esto es, una pura relación mercantil. A su vez, en tanto que concentra en sus manos un poder de compra inmenso, este agente económico particular, aglutina bajo su égida un enorme volumen de compras, un enorme volumen de intercambio con aquellos productores científicos privados, antaño dependientes de sus transferencias directas, y hoy puestos en la necesidad de vender al mejor postor los productos de su trabajo.

La escala cuantitativamente superior en la que el Estado participa del intercambio mercantil en ciencia introduce una modificación cualitativa de primer orden. Dado su poder de compra no parangonable al de cualquier otro agente económico particular ${ }^{10}$, despierta un interés

10. Véase, a este respecto, el caso de Europa. Horizon 2020 tiene presupuestados más de $80 \mathrm{mil}$ millones de euros para el periodo 2014-2020 a gastar exclusivamente en la financiación de proyectos, y no en organismos o instituciones de investigación de ningún tipo (Comisión Europea, 2014). El promedio de gasto anual se sitúa en torno a 11 mil millones de euros. No hay empresa 


\section{Tabla 2. Distribución del gasto en I+D ejecutado por las universidades entre gobierno y empresas}

\begin{tabular}{|lccc|}
\hline PAIS & $\begin{array}{c}\text { FINANCIACIÓN } \\
\text { TOTAL }\end{array}$ & $\begin{array}{c}\text { FINANCIACIÓN } \\
\text { GUBERNAMENTAL }\end{array}$ & $\begin{array}{c}\text { FINANCIACIÓN } \\
\text { EMPRESARIAL }\end{array}$ \\
\hline Japón & 20832 & $11000(52 \%)$ & $551(2 \%)$ \\
\hline Estados Unidos & 64653 & $37318(57 \%)$ & $3390(5 \%)$ \\
\hline Corea del Sur & 6887 & $5500(80 \%)$ & $850(12 \%)$ \\
\hline Alemania & 19724 & $16035(81 \%)$ & $2736(14 \%)$ \\
\hline
\end{tabular}

Fuente: Elaboración propia a partir de 'Gross domestic expenditure on R\&D by sector of performance and source of funds' (OCDE, 2019). Datos en millones de dólares a precios corrientes.

creciente entre los productores privados para intercambiar con él; pero también, como es obvio, una mayor subsunción de estos a la voluntad de aquel sujeto. El Estado actúa, entonces, como fuerza de arrastre en el ámbito de la actividad académica, quedando en posición de imponer al conjunto de los productores privados sus condiciones para que se efectúe el intercambio. Puede determinar qué se investiga y cómo se ha de desarrollar la investigación. Es ésta una capacidad que no surge del ejercicio despótico de la violencia física, sino del mismo poder de compra; emana de la relación mercantil en sí. Ahora bien, ¿cómo ejerce el Estado su demanda efectiva en el caso de la actividad académica? ¿Y cómo logra imponer la aceptación de sus exigencias al conjunto de los productores privados, sin quebrar con ello la base de la relación

que pueda acercarse, ni remotamente, a semejante guarismos de gasto en I+D. Ni tampoco Estado nacional. De ahí que los Programas Marcos de la Unión Europea para la Investigación y la Innovación, del que Horizon 2020 es el octavo, se hayan convertido en el más poderoso polo de atracción para las unidades científicas de todo el mundo. entre ambos, a saber, la libertad e independencia mutua? Es aquí donde entra en juego el "grant approach» (Stephan, 1996) del que dijimos al principio que resultaba primordial en la transformación de la estructura económica de la ciencia.

En efecto, la financiación en base a proyectos es la forma concreta que adopta el ejercicio del poder de compra estatal en el ámbito académico; y, más particularmente, la forma concreta que adopta el intercambio mercantil entre los Centros Públicos de Investigación, en tanto que «agentes de ejecución», y las administraciones públicas, en calidad de «agentes de financiación». Desde luego, existen otras formas en que la financiación pública fluye hacia la esfera de la producción científica (En Fundación COTEC, 2016, se identifican hasta cuatro modalidades); pero la financiación en base a proyectos es la forma propia y específica del nuevo modo de organización social del trabajo científico, por cuanto que es la única que vehicula realmente un intercambio entre equivalentes, la única que porta la relación social general del modo capita- 
lista de producción. Así, financiación de proyectos no sería sino el nombre que se da a la compra por parte del Estado de los productos del trabajo científico que se organiza en base a iniciativas de investigación. El producto acabado de cualquier proyecto científico son los resultados de investigación, definidos con carácter previo al desarrollo de la actividad productiva y hacia los que conscientemente se orienta todo el trabajo (presente y pretérito) movilizado en el marco de la iniciativa.

Dos propietarios de mercancías que se enfrentan entre sí, en pie de igualdad, como tales poseedores; a esto se reduce la financiación de la ciencia en base a proyectos. Pero no es menos cierto que las manifestaciones exteriores que adopta este puro intercambio mercantil parecen negar a cada paso el contenido inmanente del mismo.

Lo primero que llama la atención a este respecto, es que en el contrato que formaliza el vínculo entre las partes, el «agentes de ejecución» desgrana aquellos costes directos e indirectos en los que incurre o pronostica que incurrirá en el curso del proyecto, y es la entidad financiadora, el Estado, quien los reembolsa. Curiosa forma de desarrollarse un acto de compraventa, en efecto. Lejos de estar en presencia de un cambio de equivalentes, bien pareciese que el Estado esté entregando dinero sin equivalente alguno, sin más propósito altruista que el de sostener económicamente la actividad de los $\mathrm{CPI}^{11}$.

11. Lo cierto es que hasta esta misma apariencia está disipándose, como constata palmariamente el programa de financiación de la ciencia por excelencia en la actualidad, el VIII Programa Marco para la Investigación y la Innovación de la Unión Europea, Horizon 2020. En los últimos Work Programme, correspondientes al periodo 2018 - 2020, se ha comenzado a experimentar
Dos apreciaciones al respecto. Por un lado, hay que tomar en consideración que, conforme a la materialidad específica propia del proyecto, a duras penas puede distinguirse el resultado científico final del proceso de trabajo mismo ${ }^{12}$. A su vez, desde el punto de vista formal, el que el «agentes de ejecución» se haga abonar el desgaste de la maquinaria, los insumos empleados como materia prima, y la fuerza viva de trabajo movilizada en la iniciativa, cae dentro de lo que es propio del intercambio mercantil (con la salvedad de que estos gastos sólo se desglosan idealmente, sin necesidad de ponerlos, como aquí, por escrito); y se revela con ello, de la forma más crasa, que los medios de producción le pertenecen a él, y no al «agente de financiación» que adquiere tal

con la denominada «Lump Sum», o financiación a tanto alzado. En lugar de reembolsar costes incurridos y auditados, la entidad financiadora entrega una cantidad de dinero establecida de antemano, por el importe estimado del total de las acciones desarrolladas en el marco del proyecto. Corre a cargo de los beneficiarios, del consorcio promotor de la iniciativa, el ceñirse estrictamente al presupuesto. Más aún, al albur del «Lump Sum Model Agreement», la Comisión ha comenzado a fijar en los pliegos de condiciones de cada convocatoria el precio máximo dispuesta a pagar, como estimación del valor total, en forma de precio, de los productos del trabajo científico generados en cada caso. El modelo de financiación de proyectos se acerca cada vez más al que es propio de las licitaciones.

12. De nuevo, H2020 sirve como perfecta ilustración de lo aquí dicho. Los denominados «innovation actions» son un tipo específico de proyectos en los que no se pretende tanto ampliar el corpus de conocimiento como de aplicar soluciones tecnológicas ya existentes para la resolución de problemas específicos. Aquí, el resultado esperable es el acto mismo de producción, es decir, el que el conocimiento encuentre aplicación práctica y se logre unos ciertos efectos. 
mercancía ${ }^{13}$. Al término del intercambio, el Estado sólo es propietario de los productos del trabajo organizado en base al proyecto, no de los medios con los que éste se ha desarrollado.

La segunda particularidad de la financiación en base a proyectos tiene que ver con el modo en que el adquiriente impone sus condiciones sin quebrar con ello la naturaleza mercantil de la relación misma. Como en cualquier otra rama de la división del trabajo, el producto del trabajo científico contiene única y exclusivamente trabajo socialmente necesario; y ello, en su doble determinación, como valor de uso y como valor (cuya substancia es el trabajo abstracto, el tiempo de trabajo en general). Ocurre que, en el intercambio mercantil mediado por la financiación del proyecto de investigación, esta cualidad se verifica ex ante, con carácter previo a que se produzca la financiación del proyecto, y, desde luego, a que comience el proceso de trabajo.

Respecto del gasto de trabajo socialmente necesario como trabajo particular, en su condición de valor de uso, es el Estado, ejerciendo como «agente de financiación» (es decir, por mor del papel económico en que el mismo intercambio le sitúa), el que elabora un pliego de condiciones detallando, con mayor o menor minuciosidad, las cualidades que los productos resultantes del trabajo científico han de poseer, aquellas propiedades materiales que posibilitarán la satisfacción de sus necesidades. Al productor que desee contar con la oportunidad de enajenar su mercancía, otro remedio no le quedará que doblegarse y

13. Es el productor científico (universidad u OPI) el que tiene que demostrar a la entidad pública financiadora que cuenta con todos aquellos recursos que va a movilizar para el desarrollo del trabajo en cuestión. ceñirse a las condiciones impuestas por el comprador.

Por su parte, sólo la competencia entre los productores privados garantiza que los productos del trabajo científicos adquiridos por el Estado contengan el tiempo de trabajo abstracto indispensable. Es por ello que la financiación en base a proyectos siempre se articula en base a convocatorias públicas competitivas, a las que diferentes productores privados concurren con sus respectivas propuestas. Todas son evaluadas conforme a los parámetros fijados en el pliego de condiciones. De cuantos productores privados logren atestiguar que, en efecto, están en condiciones de proveer al demandante con un producto que satisface las exigencias de calidad establecidas, lograrán cerrar la venta aquellos capaces de hacer más con menos, los «agentes de ejecución» cuya productividad se encuentre, como mínimo, en línea con la productividad media de la rama. De ahí, precisamente, que hayan de desglosarse con sumo detalle cuáles son los costes directos e indirectos en los que incurrirán en el curso del trabajo. Es así como en la financiación en base a proyectos, se garantiza que el trabajo contenido en la mercancía, también en su cualidad abstracta de trabajo en general, de trabajo indiferenciado, es única y exclusivamente el tiempo de trabajo socialmente necesario.

Recapitulando sobre todas las conclusiones alcanzadas en este epígrafe, encontramos, en primer término, que las nuevas formas sociales de producción científica se fundamentan en el intercambio, es decir, en la relación social general del modo capitalista de producción. El metabolismo social en base al cambio de equivalentes se establece entre un «agente de finan- 
ciación» y un «agente de ejecución» cualesquiera. Este intercambio no sólo resulta en la enajenación respectiva de valores de uso particulares (de un lado, enunciados científicos fijados materialmente; del otro, dinero, el equivalente general), sino que constantemente reproduce la relación social que traban ambos sujetos; o lo que es lo mismo, la separación del productor científico respecto de sus medios de producción. El poner al productor en la necesidad de intercambiar los productos de su trabajo es exigencia ineluctable del movimiento expansivo de la relación social capitalista, de la acumulación del capital. Pero no son los capitales individuales, sino la acción estatal la que conduce a la disolución de las formas sociales tradicionales de organización del trabajo científico ${ }^{14}$. Por un lado, la acción legislativa hace de los instituciones de investigación unidades productivas formalmente independientes del Estado y su financiación discrecional e incondicionada; por otro lado, el ejercicio del poder de compra estatal reproduce constantemente la separación del trabajo científico respecto de sus condiciones laborales, haciendo necesidad de la obligación de intercambiar los productos de su actividad. La convocatoria pública de financiación de proyectos es la forma concreta que adopta la demanda efectiva del Estado en ciencia, y media la relación social de intercambio establecida entre los Centros Públicos de Investigación, como entes ejecutores del

14. Kleinman (2010) hace hincapié en que las nuevas tendencias en la organización del trabajo científico pueden rastrearse incluso en aquellas disciplinas académicas que han despertado poco o ningún interés a los capitales individuales, desde la medicina preventiva hasta la filología medieval. Allí donde el capital no ha penetrado, lo ha hecho, sin duda, el poder de compra del Estado capitalista. gasto público en I+D, y los organismos públicos como tales, en calidad de entes financiadores. En definitiva, es el dinero público el que abre paso a la relación social capitalista hacia el interior de la esfera de la producción científica.

\section{Conclusiones finales y una lectura política}

En busca de una explicación económica del imperialismo, Rosa Luxemburgo se encontró ante la necesidad de analizar el movimiento expansivo de la relación social capitalista, no en su forma más general y abstracta, sino en su despliegue por y a través de los territorios donde dominaban formas sociales de producción precapitalistas. Descubrió con ello la revolucionaria polaca que el capital requiere de mercados suplementarios en los que emplazar su plusproducto; mas no hay intercambio posible allí donde las fuerzas productivas se hallan aherrojadas a la comunidad, a la organización colectiva y planificada de la producción social. Por consiguiente, quebrar por la base las más variadas formas de economía natural que la relación social general capitalista encuentra en su desenvolvimiento se presenta como necesidad perentoria; la acción estatal media su realización. Si La acumulación del capital es una de las más brillantes producciones de la teoría marxista de todos los tiempos, ello se debe, precisamente, a que Rosa Luxemburgo fue capaz de hallar y plasmar la conexión interna y necesaria, orgánica, entre la acumulación del capital y la política imperialista.

Partiendo de las conclusiones alcanzadas por la revolucionaria polaca, este trabajo ha indagado en las transformaciones sufridas por la forma social de organización 
del trabajo científico acaecidas en las últimas décadas. Avanzando desde las manifestaciones exteriores de este proceso en su reproducción ideal mediante el pensamiento, hemos podido determinar que la potencia inmanente al mismo es la necesidad del capital de subsumir la esfera de la producción científica a la lógica de la valorización del valor, suprimiendo las formas de economía natural imperantes hasta hace apenas medio siglo. En su unidad material, la acción estatal es la que pone y reproduce de forma permanente la separación del productor científico respecto de sus medios de producción. Como coacción, obligando a los productores científicos a proveerse en el intercambio de los medios para su reproducción; como relación de cambio, para renovar constantemente el vínculo social establecido entre los productores al interior de la ciencia, el desarrollo unilateral del trabajo científico hacia el valor de cambio. El Estado, en fin, media la expansión del capital en la esfera del trabajo científico.

Existe una única lectura política que puede hacerse en relación a la transformación de la forma social de organización del trabajo científico. Siendo el Estado capitalista el agente que inocula al interior del ámbito académico la relación social general capitalista, poca ilusión cabe guardar respecto del papel que podría desempeñar frente a la «mercantilización» del conocimiento científico y del trabajo en universidades y Organismos Públicos de Investigación; en primer término, con un incremento drástico de las partidas presupuestarias destinadas a la I+D. Cualquier consideración en este sentido es un puro absurdo ideológico, una quimera de mentes febriles. La transformación de las formas sociales de producción al interior de la ciencia es un proceso necesario e ineluctable. Y confor- me a esa certeza debemos de organizar las potencias de nuestra acción en tanto que sujetos sociales en el capitalismo, y, más concretamente, como miembros de la clase obrera. Pretender una reversión al estadio de cosas previo en la academia es situarse, lisa y llanamente, en el terreno de la reacción política. Nuestra acción consciente debe de orientarse a realizar las potencias inmanentes que en el capital se contienen y que la clase obrera está llamada a materializar, a saber, la plena socialización del trabajo, la superación de la estrecha de privado e independiente con el que se realiza el trabajo social en el modo de producción capitalista (Marx, 2000). La subsunción de la ciencia al capital libera portentosas fuerzas productivas; nuestro cometido no es otro sino el de librarlas de la forma enajenada en las que el capital las desarrolla. Y el primer paso en esta acción es, precisamente, el conocimiento de su necesidad. A este propósito ha pretendido servir la investigación que aquí se concluye.

\section{Agradecimientos}

El autor de este trabajo consigna que es beneficiario de un Contrato Predoctoral concedido por la Universidad de Sevilla en el marco de su VI Plan Propio de Investigación y Transferencia (VI-PPITUS).

\section{Bibliografía}

Bush, Vannevar (1945). Science: the endless frontier. Washington, United States Government Printing Office.

Comisión Europea (2018). Horizon 2020 Programme. AGA - Annotated Model Grant Agreement, versión 5.0. Recuperado de http://ec.europa.eu/research/par- 
ticipants/data/ref/h2020/grants_manual/ amga/h2020-amga_en.pdf

(2016). Open Innovation, Open Science, Open to the World. Luxemburgo: European Commission Publishing Office.

(2014). Horizon 2020, en breve. El Programa Marco de la Investigación y la Innovación en la Unión Europea. Luxemburgo, Publications Office of the European Union.

Echevarría, Javier (2003). La revolución tecnocientífica. Madrid: Fondo de Cultura Económica.

- (2002). Ciencia y valores. Barcelona, Ediciones Destino.

Friesike, Sascha; Schildhauer, Thomas (2014). Open Science: very good resolutions, few incentives, yet, en Welpe, I.M. et al. (eds.), Incentives and performances. Governance of research organizations. Springer.

Fundación COTEC (2016). Informe COTEC 2016 [recurso electrónico]. Recuperado de: http://informecotec.es/media/ COTEC-informe-2016.pdf

Humboldt, Wilhelm Von (2005). Sobre la organización interna y externa de las instituciones científicas superiores en Berlín. LOGOS: Anales del Seminario de Metafísica, 38, pp. $283-291$.

Íñigo Carrera, Juan (2007). Conocer el capital hoy. Usar críticamente El Capital. Volumen 1: La mercancía, o la conciencia libre como forma de la conciencia enajenada. Buenos Aires, Editorial Imago Mundi.

(1992). El conocimiento dialéctico. La regulación de la acción en su forma de reproducción de la propia necesidad por el pensamiento. Buenos Aires, Centro para la Investigación Científica como Crítica Práctica.

Kleinman, Daniel Lee (2010). The commercialization of academic culture and the future of the university, en Radder, Hans (Ed.), The commodification of academic research (pp. 24-43). Pittsburgh, University of Pittsburgh Press.

Ley Orgánica 6/2001, de 21 de diciembre, de Universidades. Boletín Oficial del Estado, número 307, España, 24 de diciembre de 2001.

Luxemburgo, Rosa (1975). La acumulación del capital. Córdoba: Cuadernos de Pasado y Presente.

- (1974). Introducción a la Economía Política. México, Siglo XXI editores.

Marx, Karl (2005/1971). Elementos fundamentales para la crítica de la Economía Política: (Borrador) 1857-1858. México, Siglo XXI editores.

Marx, Karl (2000/1976). El capital. Crítica de la economía política. Barcelona, Akal.

Mattick, Paul (1977). Crítica de los neomarxistas. Barcelona, Ediciones Península.

Merton, Robert K. (1985). La estructura normativa de la ciencia, en La sociología de la ciencia (pp. 355-368). Madrid, Alianza Editorial.

Moulier-Boutang, Yann (2004), Riqueza, propiedad, libertad y renta en el capitalismo cognitivo, en Blondeau, O. et al. (eds.), Capitalismo cognitivo, propiedad intelectual y creación colectiva. Madrid, Traficante de Sueños.

Organización para la Cooperación y el Desarrollo Económicos (Mayo de 2019). Gross domestic expenditure in R\&D by sector of performance and source of funds. Recuperado de https://stats.oecd.org/Index.aspx?DataSetCode=MSTI_PUB (Mayo de 2019). Main Science \& Technology indicators. Recuperado de https://stats.oecd.org/ Index.aspx?DataSetCode=MSTI_ PUB\#\%C3\%A7

Radder, Hans (2010), The commodificacion of academic research, en The com- 
modification of academic research (pp. 1-23). Pittsburgh, University of Pittsburgh Press.

Rosdolski, Roman (1978). Génesis y estructura de El Capital de Marx. México, Siglo XXI editores.

Starosta, Guido; Caligaris, Gastón (2017). Trabajo, valor y capital. De la crítica marxiana de la economía política al capitalismo contemporáneo. Bernal: Universidad Nacional de Quilmes.

Stephan, Paula E. (1996). The economics of science, Journal of Economic review, 34 (3), pp. 1199-1235. https://www.jstor. org/stable/2729500

Tyfiled, David (2012). The economics of science, vol.1. A critical realistic overview. Nueva York: Routledge. 
